\title{
PENGEMBANGAN EDU-AGROWISATASEBAGAI KONTRIBUSI PERGURUAN TINGGI PADA PENINGKATAN KESEJAHTERAAN MASYARAKAT
}

\author{
Joniarto Parung \\ Universitas Surabaya \\ Email: jparung@staff.ubaya.ac.id \\ Gunawan \\ Universitas Surabaya \\ Arief Budhiyantoro \\ Universitas Surabaya \\ Ida Bagus Made Artadana \\ Universitas Surabaya
}

\begin{abstract}
ABSTRAK
Salah satu peran yang diharapkan masyarakat di sekitar lokasi perguruan tinggi adalah memberdayakan masyarakat sekitar sebagai wujud dari tridarma. Peran yang sama diharapkan dari kampus 3 Ubaya yang berada di daerah pegunungan Penanggungan. Program yang potensial untuk diwujudkan adalah mengintegrasikan sumberdaya kampus dengan potensi masyarakat sekitar kampus. Salahsatu potensi yang dapat mengintegrasikan potensi kampus dengan potensi masyarakat sekitar adalah Edu-Agrowisata. Upaya pertama yang dirancang adalah menyiapkan percontohan wisata pendidikan dengan memberikan pembelajaran tentang perkebunan buah dan olahannya, perikanan dan kandang komunal di dalam kampus untuk selanjutnya ditularkan kepada masyarakat sekitar. Destinasi edu-agrowisata ini didesain secara terintegratif dari satu destinasi ke destinasi lainnya secara estafet dari dalam kampus sampai ke lahan penduduk sekitar sehingga akan memberikan pengalaman pariwisata, pembelajaran dan pengetahuan umum yang lengkap bagi wisatawan. Wisata petik buah salak sebagai bagian dari edu agrowisata yang sudah dijalankan ternyata mampu meningkatkan pendapatan $600 \%$ dibandingkan hanya menjual buah salak. Keuntungan finansial ini dijadikan pintu untuk mengajak masyarakat sekitar untuk terlibat dalam jaringan destinasi edu agrowisata terintegrasi.
\end{abstract}

Kata Kunci: tridarma, edu-agrowisata, kandang komunal 


\section{PENDAHULUAN}

Potensi pasar agrowisata semakin berkembang dikalangan milenial pada 10 tahun terakhir. Perkembangan agrowista tersebut, bahkan terjadi di hampir semua beahan dunia. Sebagai contoh Mansor et.al (2015), mengatakan wisata agro memegang peranan penting untuk menggantikan wisata traditisional di Malaysia karena berbagai aktifitas agrikultur yang mendekatkan masyarakat dekat ke lokasi agrikultur, pekerjaan agrikultur, produksi agrikultur, makanan lokal dll. Hal yang sama sudah lama terjadi di China (Yang et al, 2010). Di China agro wisata adalah bentuk urban agriculuture multifungsi sebagai bagian dari pengembangan kota.

Perkembangan agro wisata di berbagai negara dipicu oleh kebutuhan rekreasi keluarga yang sehat dan bermanfaat bagi anggota keluarga. Berbagai bentuk agrowisata dengan nama berbeda dikenal di berbagai negara, misalnya wisata konversi alam (Buckley, 2011), Wisata Budaya (Richards, and Munsters, 2011), Wisata Kreatif (Richards, 2011). Tujuan utama dari semua jenis dan nama wisata tersebut, adalah meningkatkan jumlah wisatawan.

Sampai saat ini tidak banyak publikasi yang secara langsung menekan-kan tentang perlunya mengintegrasikan pendidikan (edukasi) dalam agrowisata. Makalah ini mengupas pengembangan edu-agrowisata sebagai produk perguruan tinggi.

\section{METODE PELAKSANAAN}

\section{Pengembangan Konsep Edu-Agriwisata}

Petroman et al (2016), mengusulkan wisata edukasi di daerah pertanian sebagai strategi alternatif dari wisata massal untuk daerah pedesaan. Ide tersebut dapat dikembangkan oleh perguruan tinggi di berbagai daerah yang memiliki potensi wisata lain dengan memanfaatkan potensi masyarakat sebagai wujud tridarma perguruan tinggi dalam program Edu Agrowisata. Potensi edu agrowisata menjadi hal yang menarik bagi perguruan tinggi untuk menjadi salahsatu kegiatan terintegrasi dalam melaksanakan tridarma sekaligus mening- katkan pendapatan bagi lembaga dan masyarakat. Edu agrowisata diarahkan berbasis teknologi untuk dikelola perguruan tinggi dan berbeda dengan edu agrowisata yang lain karena dapat digunakan untuk meningkatkan partisipasi sekaligus kemampuan masyarakat untuk menggunakan teknologi dalam agrowisata.

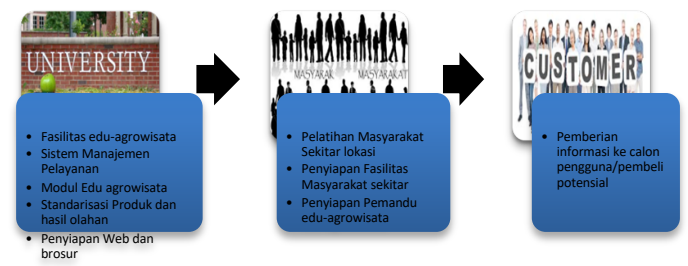

Gambar 1. Konsep Framework Edu Agrowisata Ubaya

Keberadaan Edu-agrowisata tidak terlepas dari keberadaan pembeli jasa dan/atau produk. Dalam hal ini pembeli jasa dan/atau produk adalah wisatawan yang belajar dari fasilitas yang disediakan. Perguruan tinggi yang mengikutsertakan masyarakat bertindak sebagai penyedia jasa dan sekaligus produk hasil pertanian/ perkebunan dan atau peternakan termasuk hasil olahannya. Dalam proses penyediaan jasa dan/atau produk maka perguruan tinggi harus menyiapkan masyarakat agar jasa dan produk yang ditawarkan terstandar. Secara sederhana konsep edu agrowisata dapat dilihat pada bagan di gambar 1 .

\section{Pemilihan lokasi Edu-Agrowisata}

Salah satu lokasi agrikultur yang di dalamnya mencakup pertanian, peternakan dan potensi pariwisata yang banyak dilirik di Jawa Timur adalah di kawasan Gunung Penanggungan, kecamatan Trawas, Mojokerto. Pada lokasi ini pula terletak kampus 3 Ubaya yang dikenal sebagai Integrated Outdoor Campus atau IOC. Pada awalnya, IOC merupakan lokasi training bagi mahasiswa kemudian berkembang menjadi tempat training bagi umum. Pelanggan yang mengunakan IOC sebagai lokasi training dan out bond berasal dari berbagai kalangan antara lain, sekolah (SD, SMP dan SMA), Perusahaan, BUMN, Pemerintah daerah, Polisi, TNI, dan Perguruan Tinggi. Perkembangan IOC dalam 5 tahun terakhir, menuntut perbaikan manajemen, fasilitas training dan fasilitas penunjang lainnya. 


\section{PENDAHULUAN}

Potensi pasar agrowisata semakin berkembang dikalangan milenial pada 10 tahun terakhir. Perkembangan agrowista tersebut, bahkan terjadi di hampir semua beahan dunia. Sebagai contoh Mansor et.al (2015), mengatakan wisata agro memegang peranan penting untuk menggantikan wisata traditisional di Malaysia karena berbagai aktifitas agrikultur yang mendekatkan masyarakat dekat ke lokasi agrikultur, pekerjaan agrikultur, produksi agrikultur, makanan lokal dll. Hal yang sama sudah lama terjadi di China (Yang et al, 2010). Di China agro wisata adalah bentuk urban agriculuture multifungsi sebagai bagian dari pengembangan kota.

Perkembangan agro wisata di berbagai negara dipicu oleh kebutuhan rekreasi keluarga yang sehat dan bermanfaat bagi anggota keluarga. Berbagai bentuk agrowisata dengan nama berbeda dikenal di berbagai negara, misalnya wisata konversi alam (Buckley, 2011), Wisata Budaya (Richards, and Munsters, 2011), Wisata Kreatif (Richards, 2011). Tujuan utama dari semua jenis dan nama wisata tersebut, adalah meningkatkan jumlah wisatawan.

Sampai saat ini tidak banyak publikasi yang secara langsung menekan-kan tentang perlunya mengintegrasikan pendidikan (edukasi) dalam agrowisata. Makalah ini mengupas pengembangan edu-agrowisata sebagai produk perguruan tinggi.

\section{METODE PELAKSANAAN}

\section{Pengembangan Konsep Edu-Agriwisata}

Petroman et al (2016), mengusulkan wisata edukasi di daerah pertanian sebagai strategi alternatif dari wisata massal untuk daerah pedesaan. Ide tersebut dapat dikembangkan oleh perguruan tinggi di berbagai daerah yang memiliki potensi wisata lain dengan memanfaatkan potensi masyarakat sebagai wujud tridarma perguruan tinggi dalam program Edu Agrowisata. Potensi edu agrowisata menjadi hal yang menarik bagi perguruan tinggi untuk menjadi salahsatu kegiatan terintegrasi dalam melaksanakan tridarma sekaligus mening- katkan pendapatan bagi lembaga dan masyarakat. Edu agrowisata diarahkan berbasis teknologi untuk dikelola perguruan tinggi dan berbeda dengan edu agrowisata yang lain karena dapat digunakan untuk meningkatkan partisipasi sekaligus kemampuan masyarakat untuk menggunakan teknologi dalam agrowisata.

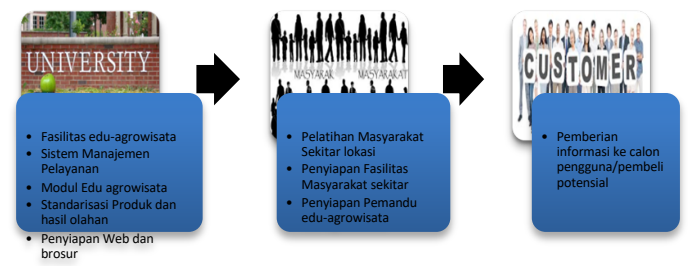

Gambar 1. Konsep Framework Edu Agrowisata Ubaya

Keberadaan Edu-agrowisata tidak terlepas dari keberadaan pembeli jasa dan/atau produk. Dalam hal ini pembeli jasa dan/atau produk adalah wisatawan yang belajar dari fasilitas yang disediakan. Perguruan tinggi yang mengikutsertakan masyarakat bertindak sebagai penyedia jasa dan sekaligus produk hasil pertanian/ perkebunan dan atau peternakan termasuk hasil olahannya. Dalam proses penyediaan jasa dan/atau produk maka perguruan tinggi harus menyiapkan masyarakat agar jasa dan produk yang ditawarkan terstandar. Secara sederhana konsep edu agrowisata dapat dilihat pada bagan di gambar 1 .

\section{Pemilihan lokasi Edu-Agrowisata}

Salah satu lokasi agrikultur yang di dalamnya mencakup pertanian, peternakan dan potensi pariwisata yang banyak dilirik di Jawa Timur adalah di kawasan Gunung Penanggungan, kecamatan Trawas, Mojokerto. Pada lokasi ini pula terletak kampus 3 Ubaya yang dikenal sebagai Integrated Outdoor Campus atau IOC. Pada awalnya, IOC merupakan lokasi training bagi mahasiswa kemudian berkembang menjadi tempat training bagi umum. Pelanggan yang mengunakan IOC sebagai lokasi training dan out bond berasal dari berbagai kalangan antara lain, sekolah (SD, SMP dan SMA), Perusahaan, BUMN, Pemerintah daerah, Polisi, TNI, dan Perguruan Tinggi. Perkembangan IOC dalam 5 tahun terakhir, menuntut perbaikan manajemen, fasilitas training dan fasilitas penunjang lainnya. 
Edu-Agrowisata IOC UBAYA merupakan sebuah bentuk wisata pendidikan yang memberikan pembelajaran tentang perkebunan buah dan olahannya, perikanan lele dan peternakan sapikambing yang dikemas dalam paket kandang komunal. Destinasi eduagrowisata ini didesain secara terintegratif dari satu destinasi ke destinasi lainnya secara estafet sehingga akan memberikan pengalaman pariwisata, pembelajaran dan pengetahuan umum yang lengkap bagi wisatawan. Secara lengkap 7 destinasi EduAgrowisata IOC UBAYA diberikan pada diagram dalam Gambar 2.

\section{DESAIN DESTINASI EDU-AGROWISATA IOC UBAYA}

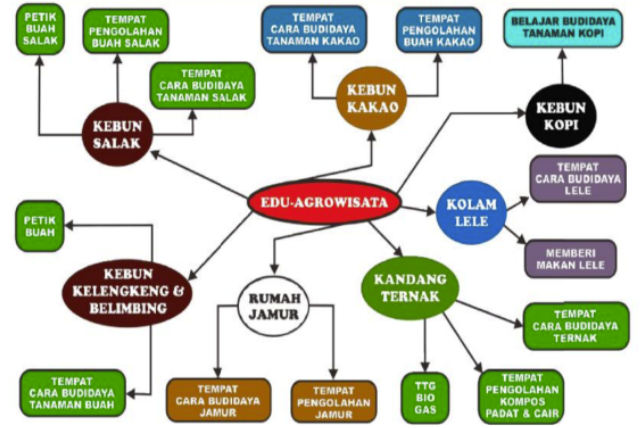

Gambar 2. Desain The Farm, destinasi EduAgrowisata IOC UBAYA

Destinasi dalam kampus diberi nama The Farm, untuk memberikan gambaran wisata yang akan dihadapi sekaligus memberi nama yang memiliki gambaran singkat dan mudah diingat, sesuai pengalaman yang dialami pengunjung. Destinasi ini dirangkaikan dengan destinasi lain milik masyarakat sekitar kampus. Keberadaan destinasi edu-agrowisata ini akan memicu pergerakan ekonomi masyarakat sekitar karena Konsumsi dan souvenir khas akan berkembang di kalangan masyarakat sekitar yang dipicu pertumbuhan demand.

\section{HASIL PENERAPAN}

Destinasi Edu agrowisata IOC Ubaya secara fisik diselesaikan dalam 2 tahun. Destinasi kebun salak dan kebun kopi sudah bisa dioperasionalkan karena pekerjaan fisik hanya menata track pengunjung dalam lokasi yan sudah ada sebelumnya. Destinasi lainnya membutuhkan waktu pembangunan fasilitas fisik dan penanaman dalam waktu 2 tahun sehingga sekarang masih menunggu waktu untuk operasional.

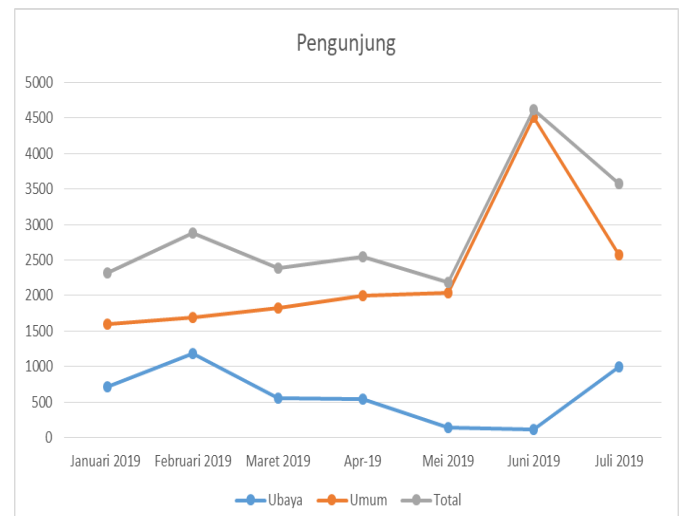

Gambar.3 Perkembangan Pengunjung

Pembentukan Edu-Agrowisata Ubaya sudah berhasil:

1. Memperkuat unit Income generating bagi IOC UBAYA, khususnya dari wisata petik salak sambil belajar tentang buah salak yang sudah dioperasional-kan. Data pengunjung selama tahun 2019 dapat dilihat pada gambar 3. Biaya untuk memasuki wisata petik salak bernilai 5 kali harga salak perkilo. Jumlah pengunjung ini meningkatkan pendapatan kebun salak hingga $600 \%$ dibandingkan menjual salak sebagai buah saja.

2. Mengimplementasi hasil-hasil karya dosen UBAYA dalam EduAgrowisata IOC UBAYA. Keberadaan edu-agro-wisata telah meningkatkan motivasi dosen Ubaya khususnya dari fakultas Teknobiologi untuk menghasilkan modul pelatihan dan buku buku terkait edu agrowisata (Gambar.4) 


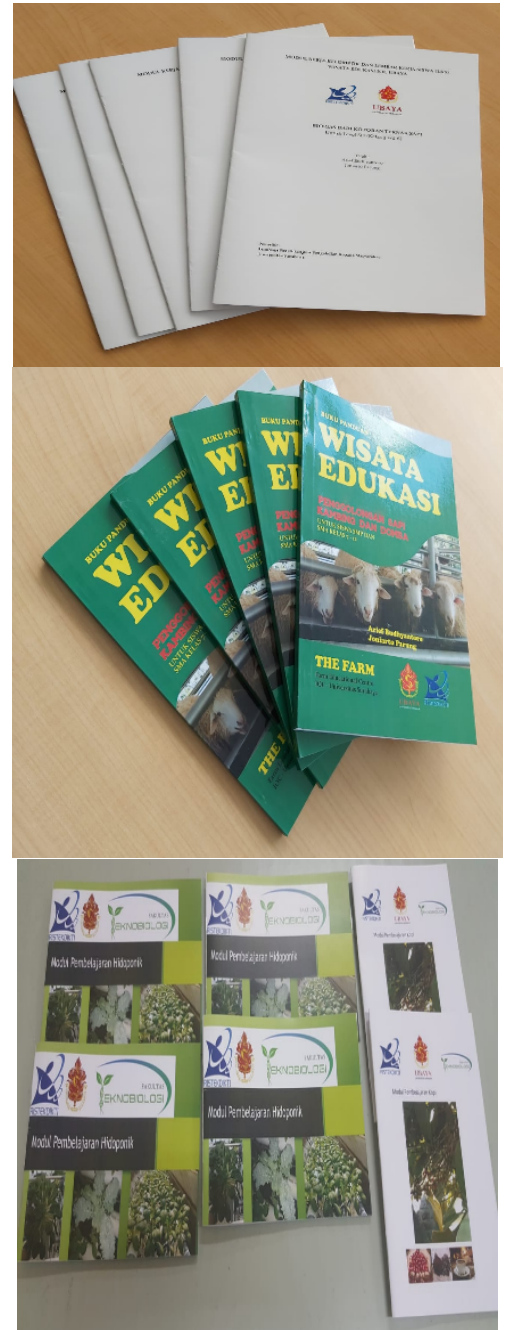

Gambar. 4 Buku dan Modul pelatihan

3. Memperkuat sinergi dan kerjasama antara IOC UBAYA dengan masyarakat sekitar yang bertujuan meningkatkan kesejahteraan masyarakat sekitar. Kebun masyarakat dimasukkan dalam tujuan wisata edukasi yang diawali dengan pelatihan menjadi pemandu wisata edu-kasi, dilanjutkan dengan penataan kebun agar mudah dijadikan tempat pembelajaran.

4. Memperkenalkan tentang Edu-Agrowisata secara praktis kepada anakanak dan keluarga yang mengadakan kunjungan ke IOC.

\section{PENUTUP}

Terimakasih kami sampaikan kepada Kemenristek Dikti khususnya DRPM yang telah membiayai program PUPPIK ini sesuai kontrak No.004/SP2H/PPM/L7/2019

\section{KESIMPULAN}

Edu-agrowisata yang terbuka untuk umum dan membidik khusus pelajar dan keluarga yang mencari hiburan dan pendidikan dikategorikan sebagai bentuk alternatif wisata di daerah pedesaan yang yang memberi dampak ekonomi selain tetap membantu pemeliharaan lingkungan. Edu agrowisata memberi pengalaman langsung dalam pembelajaran sekaligus pengamatan langsung bagi pengunjung yang hadir untuk belajar.

Edu-agrowisata adalah bentuk program multifungsi bagi perguruan tinggi karena dapat berfungsi sebagai tempat pendidikan, tempat pengabdian kepada masyarakat, sumber pendapatan alternatif dan tempat wisata bagi mereka yang mencari ketenangan daerah pedesaan dan pada saat yang sama tertarik pada budaya pedesaan tradisional.

\section{REFERENSI}

Mansor, N.; Rashid, K.M.; Zuraida, M.; Zalinawati' A. 2011. Agro Tourism Potential in Malaysia, International Academic Research Journal of Business and Technology 1(2) 2015, Page 37-44

Petroman, L; Varga, M.; Constantin, C.E.; Petroman, C; Momir, B.; Turc, B.; Merce, L. 2016. Agritourism: An Educational Tool for the Students with Agro-Food Profile, Procedia Economics and Finance 39 (2016) $83-87$

Ralf Buckley, R. 2011. Conservation Tourism. Annals of Tourism Research, Vol. 38, No. 4, pp. 1675-1676

Richards, G. and Munsters, W. 2011. Cultural Tourism Research Methods, Annals of Tourism Research, Vol. 38, No. 4, pp. 1669-1671, 2011

Richards, G. 2011. Creativity and Tourism The State of the Art. Annals of Tourism Research, Vol. 38, No. 4, pp. 1225-1253

Yang, Z.; Cai, J.; Sliuzas, R. 2010. Agrotourism enterprises as a form of multifunctional urban agriculture for periurban development in China. Habitat International 34 (2010) 374e385 